\title{
Efecto de la deficiencia de hierro sobre el desarrollo neuropsicológico en lactantes
}

\section{Effect of iron deficiency on neuropsychological development in infants}

\author{
Beatriz Beltrán-Navarro ${ }^{1}$, Esmeralda Matute $^{2}$, Edgar M. Vásquez-Garibay $^{3}$
}

\begin{abstract}
${ }^{1}$ Licenciada en Psicología Educativa. Maestra y Doctora en Ciencias del Comportamiento (orientación Neurociencias). Profesor Investigador Asociado C del Departamento de Neurociencias del Centro Universitario de Ciencias de la Salud de la Universidad de Guadalajara, Guadalajara, Jalisco, México. E-mail: beatrizbeltran@hotmail.com
\end{abstract}

${ }^{2}$ Licenciada en Educación Especial. Doctora en Neuropsicología y Neurolingüística. Profesor Investigador Titular C y Directora del Instituto de Neurociencias del Centro Universitario de Ciencias Biológicas y Agropecuarias de la Universidad de Guadalajara, Guadalajara, Jalisco, México. E-mail: ematute@redudg.udg.mx

${ }^{3}$ Médico cirujano y partero. Pediatra. Maestro en Ciencias Médicas y Doctor en Ciencias de la Salud. Posdoctoral Fellow Research on Pediatric Nutrition. Profesor Investigador Titular C y Director del Instituto de Nutrición Humana del Centro Universitario de Ciencias de la Salud de la Universidad de Guadalajara, Guadalajara, Jalisco, México.

E-mail: vasquez.garibay@gmail.com

\section{Resumen}

La deficiencia de hierro (DFe) es la patología nutrimental infantil de mayor prevalencia en el mundo y afecta la maduración cerebral y el consiguiente desarrollo cognitivo, lingüístico, motor y comportamental de quienes la padecen. El informe que se presenta tuvo como objetivo estudiar, en profundidad, literatura acerca del efecto de la DFe sobre el desarrollo neuropsicológico en lactantes. Para ello, se analizaron 51 estudios originales realizados en humanos, 49 de los cuales fueron obtenidos a través de Pubmed y 2, de SciELO. Cabe resaltar que, con el fin de discutir los hallazgos de estos artículos, se incluyeron investigaciones sobre el efecto de la DFe que utilizan modelo animal, así como estudios en humanos con desarrollo típico.
Esta búsqueda se realizó a conveniencia. El reconocimiento de sus implicaciones facilitaría el trabajo terapéutico, así como la inclusión de programas de estimulación temprana junto con el manejo de la deficiencia nutrimental.

Palabras clave: Hierro; Anemia; Lactantes; Sistema nervioso central; Desarrollo neuropsicológico.

\section{Abstract}

Iron is involved in various aspects related to brain function, including oxygen transport, neurotransmitters metabolism, DNA synthesis, ATP production, dendritic growth, axonal development and transport, myelin production, glial development, in plasticity 
markers such as the brain-derived growth factor, and in synaptic plasticity. Human development (biological, cognitive, social) is associated with a bidirectional and dynamic interaction between gene activity, neural activity and environment. An environmental variable is nutrition, and it is known that the central nervous system is extremely vulnerable to nutritional deficiencies during pregnancy and in the first two years of life, period in which an accelerated maturational dynamism occurs. Therefore, a disturbance of these by an iron deficiency would result in neuropsychological alterations, with varied expressions depending on the age at which it occurs and the severity and duration of the nutritional disease. Iron deficiency is defined as the depletion of iron reserves in the body by various factors (nutritional, physiological, pathological, etc.). Three stages of the illness have been established: iron depletion, iron deficiency without anemia and iron deficiency anemia. The first is associated with a decrease in iron reserves without reaching the deficiency; it may be due to a reduction in iron intake and or absorption, excessive loss or an increase in iron requirements. At this stage, there are no functional consequences in the organism. The second stage, is characterized by biochemical changes that reflect a pathologically reduced concentration of serum ferritin with a normal hemoglobin concentration. Finally, iron deficiency anemia is defined by the combination of low concentration of serum ferritin and hemoglobin. Given that iron deficiency is the most prevalent childhood nutritional disorder in the world (affecting $43 \%$ of children aged 6-59 months) and that it impacts brain maturation and the consequent cognitive, linguistic, motor and behavioral development of those who suffer from it, in this paper, the literature on the effect of iron deficiency on neuropsychological development in infants is analyzed in depth. The review was performed conside- ring the short, medium and long lasting effects of iron deficiency without anemia, iron deficiency anemia, chronic iron deficiency during the first two years of life and the presence of treatment. To contextualize, the analysis of the relationship between iron and brain functioning is included and the variables that modulate the expression of its effect are addressed. To carry out the search of literature regarding the effect of iron deficiency on neuropsychological development in infants, Pubmed and SciELO were consulted. No date or language restriction was established. Different combinations of terms were used: "iron deficiency infant", "iron deficiency fetal", "iron deficiency neonatal", "iron deficiency long lasting". The analyzed reports fulfilled the following inclusion criteria: a) primary sources, b) establish a value of hemoglobin and at least one of iron (i.e, serum ferritin, mean corpuscular volume, free erythrocyte, protoporphyrin, transferrin saturation) to define the children of each group, c) human sample, d) description of the measures used for the evaluation, e) studies examined after this stage, had to determine that the sample evaluated presented iron deficiency during the first two years of life. In this paper, 51 original articles conducted in humans were analyzed, of which 49 were obtained through Pubmed and 2 from SciELO. It should be noted that, in order to discuss the findings of these reports, literature was included on the effect of iron deficiency using animal models, as well as studies in humans with typical development. The search for these was done at convenience. The recognition of its implications would facilitate the therapeutic work, as well as the inclusion of early stimulation programs together with the management of nutritional deficiency.

Keywords: Iron; Anemia; Infants; Central nervous system; Neuropsychological development. 


\section{Introducción}

La deficiencia de hierro (DFe) está catalogada como la patología nutrimental infantil de mayor prevalencia en el mundo, presente en países tanto industrializados como menos industrializados (WHO, 2001). Actualmente, se infiere su prevalencia utilizando a la anemia como indicador indirecto. La Organización Mundial de la Salud (OMS) reportó en 2011, que en el ámbito mundial había $43 \%$ (273 millones) de niños entre seis y 59 meses de edad con anemia. De ellos, el $50 \%$ tenían DFe como factor contribuyente y se concentraba en aquellos pertenecientes al rango de seis a 24 meses de edad. Además, el $38 \%$ (32 millones) de mujeres embarazadas presentaban anemia; de estas, el $60 \%$ tenían DFe como elemento participante (WHO, 2015).

Ahora bien, el desarrollo de los individuos (biológico, cognitivo, social) está sujeto a una interacción bidireccional y dinámica entre la actividad del gen, la actividad neural y el ambiente (Gottlieb y Lickliter, 2007). Una variable ambiental es la alimentación y se sabe que el sistema nervioso central (SNC) es extremadamente vulnerable a las deficiencias nutrimentales durante la gestación y los primeros dos años de vida, etapa en la que se encuentra en un dinamismo maduracional acelerado. Así, al tener el estado nutricio un impacto sobre la maduración del SNC, afecta al desarrollo neuropsicológico (cognitivo, lingüístico, motriz y comportamental). Por ello, la DFe es un problema de Salud Pública, sobre todo por su elevada prevalencia en esta etapa crucial de la vida para la maduración del SNC y el desarrollo neuropsicológico.

En este escrito se realizó una revisión de literatura acerca del efecto de la DFe sobre el desarrollo cognitivo, lingüístico, motor y comportamental en lactantes (rango de edad desde el segundo mes después del nacimiento a los 23 meses 29 días de edad). Para ello, se definieron los criterios de DFe sin anemia (DFe sin-A) y de anemia por DFe (ADFe). Enseguida se estableció la importancia del hierro para el funcionamiento cerebral. También se analizaron los cambios ligados a la DFe sin-A, la $\mathrm{ADFe}$ y la $\mathrm{DFe}$ crónica ocurrida durante los primeros dos años de vida, sobre el neurodesarrollo a corto, mediano y largo plazo y, por último, se cerró con el reporte de las variables ambientales y biológicas que se han reconocido como moduladoras de su expresión. El reconocimiento de sus implicaciones facilitará la inclusión de programas de estimulación temprana junto con el manejo de la deficiencia nutrimental.

\section{Método}

Para realizar la búsqueda de literatura referente al efecto de la DFe sobre el desarrollo neuropsicológico en lactantes y los cambios ligados a mediano y largo plazo, se consultaron Pubmed y Scielo. No se estableció restricción de fecha o idioma. Se utilizaron diferentes combinaciones de términos: iron deficiency infant, iron deficiency fetal, iron deficiency neonatal, iron deficiency long lasting. Los trabajos analizados cumplieron los siguientes criterios de inclusión: a) fuentes primarias, b) determinar un valor de hemoglobina y al menos uno de hierro (como, por ejemplo, ferritina sérica, volumen corpuscular medio, amplitud de distribución eritrocitaria, índice de saturación de transferrina) para definir a los niños de cada grupo, c) muestra humana, d) describir las medidas utilizadas para la evaluación, e) los artículos examinados después de esta etapa, tenían que establecer que la muestra evaluada había presentado DFe durante la lactancia. La búsqueda generó en Pubmed, $\mathrm{n}=3945$ de iron deficiency infants, $\mathrm{n}=679$ de iron deficiency fetal, $\mathrm{n}=1439$ de iron deficiency neonatal, y $\mathrm{n}=30$ de iron deficiency long lasting; $\mathrm{y}$ en Scielo, $\mathrm{n}=98$ de iron deficiency infants, $\mathrm{n}=23$ de iron deficiency fetal, $\mathrm{n}=19$ de iron deficiency neonatal, $\mathrm{y}$ $\mathrm{n}=1$ de iron deficiency long lasting. En la presente investigación se analizaron 51 estudios originales realizados en humanos, de ellos 49 fueron obtenidos a través de Pubmed y 2 de 
Scielo. Cabe resaltar que, con el fin de discutir los hallazgos de estos artículos, se incluyeron investigaciones sobre el efecto de la DFe que utilizan modelo animal, así como estudios en humanos con desarrollo típico. Esta búsqueda se realizó a conveniencia.

\section{¿Qué es la DFe?}

La DFe es el agotamiento de las reservas de hierro en el organismo por diversos factores (nutricios, fisiológicos, patológicos, etc.). El estado nutricio con carencia de hierro se divide en tres etapas: depleción de la reserva de hierro, DFe sin-A y ADFe. La primera se asocia a una disminución en las reservas de hierro sin llegar a la deficiencia; puede ser debida a una reducción en la ingestión y/o absorción de hierro, a una pérdida excesiva o un aumento en los requerimientos de hierro. En esta etapa no hay consecuencias funcionales en el organismo (ferritina sérica $12 \mathrm{~g} / \mathrm{L}$ y hemoglobina $11 \mathrm{~g} / \mathrm{dL})$. La segunda está caracterizada por cambios bioquímicos que reflejan una concentración patológicamente disminuida de ferritina sérica $(<12 \mathrm{~g} / \mathrm{L})$ con una concentración de hemoglobina normal $(\geq 11 \mathrm{~g} / \mathrm{dL})$. Finalmente, la ADFe se define por la combinación de concentración baja de ferritina sérica $(<12 \mathrm{~g} / \mathrm{L})$ y de hemoglobina $(<11 \mathrm{~g} / \mathrm{dL})(\mathrm{WHO}, 2001)$.

\section{La importancia del hierro para el funcionamiento cerebral}

Durante el embarazo, es trascendente una adecuada nutrición y suplementación con hierro. En este periodo, la gestante presenta cambios importantes en la concentración de hemoglobina, la cual disminuye durante el primer trimestre, alcanza su punto más bajo en el segundo y aumenta de nuevo en el tercero (WHO, 2011). Aun cuando el transporte de hierro de la placenta al producto inicia desde el primer trimestre, es durante el tercero cuando ocurre un incremento significativo; de ahí que dos tercios del total de hierro corporal presente en el neonato nacido a término se acumuló en este último trimestre (Rao y Georgieff, 2001). La OMS (2001) indica que, durante el embarazo, el parto y el periodo perinatal, tanto la madre como el producto requieren una cantidad total de aproximadamente 700-850 mg de hierro. Ciertas condiciones gestacionales (ingesta inadecuada de hierro, alto contenido de fibra en la dieta, enfermedad parasitaria, hipertensión, diabetes mellitus, fumar, embarazo múltiple, nacimiento prematuro, etc.) asociadas con la disminución del suministro de hierro fetal y/o aumento de la demanda de hierro fetal más allá de la capacidad de transporte placentario, pueden dar lugar a una DFe prenatal (Rao y Georgieff, 2007). Esta es definida en el primer y tercer trimestre con valor de hemoglobina menor a $110 \mathrm{~g} / \mathrm{L}$, y en el segundo trimestre, con hemoglobina menor a $115 \mathrm{~g} / \mathrm{L}$ (WHO, 2016). Cuando el suministro de hierro materno-fetal es inadecuado para apoyar la eritropoyesis, se produce el agotamiento de hierro tisular almacenado y no almacenado (Rao y Georgieff, 2007).

Con relación al SNC, el hierro es un micronutrimento involucrado en diversos procesos metabólicos cerebrales, como el transporte de oxígeno (Antonides et al., 2015); el transporte de electrones que facilita el metabolismo aeróbico celular en la producción de ATP (Barañano et al., 2000); el metabolismo de neurotransmisores, como la serotonina, norepinefrina (Burhans et al., 2005), dopamina (Beard, Erikson y Jones, 2003), glutamato y GABA (Mittal, Pandey, Mittal, y Agarwal, 2002); el crecimiento dendrítico (Jorgenson, Wobken y Georgieff, 2003); el desarrollo (Lee, Strathmann, Gelein, Walton y Mayer-Proschel, 2012) y transporte axonal (Moos y Rosengren Nielsen, 2006); la producción de mielina (Beard, Wiesinger y Connor, 2003), el desarrollo de la microglía y los astrocitos (Rosato-Siri et al., 2017); en marcadores de plasticidad como el factor de crecimiento derivado del cerebro, su receptor tipo tirosina quinasa B, $y$ el receptor de neurotrofina p75 en regiones 
hipocampales (Nelissen et al., 2017); en la plasticidad sináptica, a través de la generación de señales de calcio mediadas por receptores de rianodina después de la estimulación del receptor de N-metil-D-aspartato, lo que a su vez promueve la activación de ERK1/2, un paso esencial para la potenciación y sostenimiento a largo plazo (Muñoz et al., 2011), entre otros. Por ello, una perturbación de estos, por una $\mathrm{DFe}$, se traduciría en alteraciones neuropsicológicas, cuya expresión variará tanto por la edad en que ocurre como por la severidad y duración de la patología de origen nutricio.

\section{Efecto de la DFe prenatal sobre el desarrollo neuropsicológico después del nacimiento}

La DFe durante el embarazo ha sido vinculada con algunos aspectos del comportamiento neonatal y este efecto varía en dependencia del momento de gestación en el que la DFe acontece; en aquellos neonatos cuyas madres presentaron DFe durante el primer o segundo trimestre de embarazo, se observó alterada la respuesta autónoma que indica inmadurez cerebral (mayor temblor, nerviosismo y variación en la respuesta del color de la piel), mientras que aquellos de madres con DFe en el tercer trimestre de gestación, mostraron dificultades en el comportamiento motor, así como falla en la autorregulación (Hernández-Martínez et al., 2011). Santos et al. (2018) concuerdan con lo anterior y establecen que el efecto se sigue observando en edades posteriores, pues lactantes con DFe fetal-neonatal y DFe fetal-neonatal-y a los 9 meses de edad (mayor duración), presentaron menores puntajes en tareas de locomoción. Aquellos del segundo grupo, también exhibieron menor desempeño en reactivos de motricidad gruesa. Finalmente, indicaron que la severidad de DFe materna en el tercer trimestre de gestación se asoció con menores puntajes de desarrollo motor y comportamientos vestibulares. Sugirieron que dificultades en los procesos de mielinización podrían explicar estos patrones.
Es bien sabido que los oligodendrocitos requieren que el hierro sintetice ácidos grasos y colesterol para la producción de mielina, la cual es necesaria para tener mayor velocidad en la conducción neural (Roncagliolo et al., 1998). En humanos, la estructura y conectividad de las vías reflejas y vestibulares, ya se observan al momento del nacimiento. La activación del sistema vestibular, el cerebelo y el sistema reticular se integran a través de las vías vestibuloespinales para proporcionar equilibrio y coordinar la locomoción. Las vías corticoespinales no están completamente mielinizadas al nacimiento, y su progresiva mielinización posnatal (después del nacimiento), impacta directamente en la motricidad gruesa, siendo éstas sensibles a un insulto como la DFe (Santos et al., 2018). A mediano plazo, este efecto también ha sido evidente (Tamura et al., 2002), a través de una asociación entre el estado nutricio de hierro neonatal y bajo desempeño de desarrollo mental y psicomotor a los cinco años de edad. Lo anterior sugiere que una inadecuada concentración de hierro durante el embarazo podría conducir a un efecto duradero, por lo menos a mediano plazo, sobre el desarrollo neuropsicológico.

Sobre la memoria, Geng et al. (2015) revelaron la potencial existencia de dificultades en niños de dos meses de edad con DFe sin-A al nacimiento, pues no encontraron evidencia electrofisiológica de reconocimiento de la voz de la madre a diferencia de aquéllos con ENFeN. Esta falla en la memoria podría ser explicada por una afectación en la maduración del hipocampo, pues se ha planteado un paralelismo entre esta y el desarrollo de la memoria (Thompson et al., 2013). Dado que el desarrollo más rápido del hipocampo ocurre en los meses perinatales (Thompson et al., 2013), durante el embarazo, esta región es vulnerable a las deficiencias nutricias (Deboer et al., 2005); de hecho, la reducción del volumen en el desarrollo del hipocampo ha sido vinculada con dificultades de la memoria en niños (Thompson et al., 2008). 


\section{Efecto de la DFe sin anemia durante la lactancia sobre el desarrollo neuropsicológico}

El efecto de la DFe sin-A en lactantes ha sido analizado a través de diferentes medidas asociadas con el desarrollo cognitivo, motor y comportamental. Aun cuando se ha señalado que a mayor intensidad de la DFe, mayor es el efecto nocivo sobre el desarrollo (Baptista-González et al., 2004; Lozoff et al., 2008; Shafir et al., 2008), en una muestra con DFe sin-A con un amplio rango de edad -de seis a 30 meses- sin considerar el nivel de severidad de la DFe sin-A (Akman et al., 2004), se observó un desempeño más bajo en la Escala Mental de Bayley (1993) y en la Escala de Desarrollo Denver (Frankenburg y Dodds, 1992) en comparación con una muestra homóloga con estado nutricio de hierro normal (ENFeN); no obstante, este efecto no se advirtió en muestras de lactantes con un rango de edad más estrecho: 12 a 15 meses (Walter, De Andraca, Chadud y Perales, 1989), 12 a 23 meses (Lozoff et al., 1987) y 14 a 18 meses (Beltrán-Navarro, Matute, Vásquez-Garibay y Zarabozo, 2012), lo que podría estar relacionado con la variabilidad entre individuos que se ha reportado en dominios cognitivos en edades tempranas (Fenson et al., 2000).

También se ha revelado un efecto adverso consistente de la DFe sin-A sobre la motricidad, a través, tanto de observaciones en casa, por ejemplo, baja actividad motora de lactantes de entre cinco y 19 meses de edad (Olney et al., 2007), como con el uso de escalas motoras, en niños de edades de seis a ocho meses (Baptista-González et al., 2004) y de nueve a 10 meses (Shafir et al., 2008); o bien, con herramientas más informales como la evaluación de los hitos del desarrollo motor grueso y una tarea de recuperación de un juguete, en lactantes de entre nueve y 10 meses de edad, cuando fueron contrastados con niños de edades semejantes con ENFeN
(Shafir et al., 2008). El cerebelo es una estructura del SNC que está implicada en la coordinación y el equilibrio motor; el núcleo caudado (Knickmeyer et al., 2008) a su vez, contribuye a la postura corporal y de los miembros, a la velocidad y exactitud de los movimientos voluntarios, y a la integración de la información mnemónica codificada espacialmente con la preparación de la actividad motora para guiar el comportamiento (Postle y D'Esposito, 1999). El acelerado desarrollo de estas estructuras en el primer año de vida (Knickmeyer et al., 2008) sugiere que este puede ser un momento de mayor vulnerabilidad para ellas, de allí que este dominio resulte afectado.

Con relación a los rasgos comportamentales, Armony-Sivan et al. (2016) encontraron conductas asociadas con aislamiento $\mathrm{y}$ emociones negativas en lactantes de nueve meses de edad con antecedentes de DFe sin-A prenatal y posnatal, al cotejarlos con niños que pertenecían a los grupos de solo DFe sin-A prenatal o solo DFe sin-A posnatal y aquellos que no presentaron DFe. Características similares fueron observadas entre los nueve y 12 meses de edad, pues los lactantes con DFe sin-A se demoraron más para calmarse si se enojaban o lloraban y mostraron menor interés y atención hacia la exploración del entorno en contraste con niños con ENFeN (Lozoff et al., 2008). Finalmente, Deinard et al. (1981) indicaron comportamiento de aislamiento y temor ante nuevas situaciones o nuevas personas, en lactantes entre 11 y 13 meses de edad con DFe sin-A severa, al contrastarlos con aquellos con DFe sin-A moderada y ENFeN. Se ha propuesto que la afectación a nivel del comportamiento tiene una doble implicación; por una parte, el efecto directo de la DFe sobre el cerebro en desarrollo afectaría la adquisición de nuevos aprendizajes y por otra, el efecto indirecto, dada la limitación en la interacción con el ambiente, alteraría en el desarrollo cognitivo, motor y comportamental ulterior (Lozoff et al., 2008). 


\section{Efecto de la ADFe durante la lactancia sobre el desarrollo neuropsicológico}

Hallazgos ligados a la cognición, indican un bajo desempeño en las pruebas cognitivas en las edades entre seis y 30 meses (Akman et al., 2004), 12 y 15 meses (Walter et al., 1989), 12 a 23 meses (Lozoff et al., 1987) y 19 a24 meses (Lozoff et al., 1982) en los niños con $\mathrm{ADFe}$ cuando se compararon con aquéllos con ENFeN y DFe sin-A. De igual modo, se han señalado efectos adversos de la $\mathrm{ADFe}$ sobre aspectos cognitivos específicos, como memoria de reconocimiento y detección de la permanencia del objeto en lactantes de nueve a 12 meses de edad, cuando se cotejaron con niños con ENFeN y con DFe sin-A (Carter et al., 2010). De igual forma, a la edad de nueve meses, Burden et al. (2007) observaron menor atención y memoria de reconocimiento en estos niños en contraste con lactantes con ENFeN. Además, Lozoff et al. (2010) infirieron que una menor tasa de parpadeo espontáneo (que se considera una medida no invasiva de funcionamiento dopaminérgico) en lactantes con ADFe entre los nueve y 10 meses de edad, sugería una afectación de los procesos de atención, habilidades espaciales y flexibilidad cognitiva.

Con relación al lenguaje, Walter et al. (1989) reportaron un desempeño bajo a los 12 meses de edad en el reactivo 106 (imita palabras), y a los 15 meses de edad en el reactivo 113 (dice dos palabras con sentido) de la Escala Mental de Bayley (1993) en lactantes con $\mathrm{ADFe}$, en comparación con aquellos con ENFeN. Con esta misma escala, Beltrán-Navarro et al. (2012) observaron que ninguno de los nueve lactantes evaluados de 14 a 18 meses de edad con ADFe logró vocalizar dos palabras o imitar una oración de dos palabras, en tanto que ocho participantes de la misma edad con ENFeN, sí lo consiguieron. Stoltzfus et al. (2001) proponen que el rezago en la expresión verbal ante ADFe podría revertirse a través de la suplementación con hierro por 12 meses.
En cuanto a la motricidad, varios autores (Akman et al., 2004; Lozoff et al., 1987; Walter et al., 1989) reportaron un desfase en el desarrollo motor medido a través de la Escala Motora de Bayley (Bayley, 1993) en lactantes y preescolares con edades entre los 6 y 30 meses, con $\mathrm{ADFe}$ en contraste con aquellos con ENFeN y con DFe sin-A. El uso de otras escalas, tales como la de Desarrollo Motor Peabody (Folio y Fewell, 2000) y la Batería Infantil Neurológica Internacional (Ellison, 1994), así como del uso de una tarea de coordinación bimanual (Shafir et al., 2008) han arrojado datos similares. Estos hallazgos coinciden con los propios del estudio longitudinal de Stoltzfus et al. (2001) en participantes de 12 a 36 meses de edad con ADFe a través de una escala motora compuesta por reactivos de la Escala Griffiths (Griffiths, 1970) y la Escala de Desarrollo McCarthy (McCarthy, 1972). Lo interesante fue que después de 12 meses de suplementación diaria con hierro, sólo aquellos con concentraciones iniciales de hemoglobina menores a $90 \mathrm{~g} / \mathrm{L}$ incrementaron sus puntajes en el retest. De igual manera, este desfase motor se ha advertido en el entorno cotidiano $\mathrm{y} / \mathrm{o}$ en conductas específicas; por ejemplo, menor actividad motora durante la vigilia, medida a través de actígrafos en tobillos (Angulo-Kinzler et al., 2002), inicio tardío de la locomoción bipedal (Kariger et al., 2005; Walter et al., 1989) y en la posibilidad de pasar de la posición de acostado a la de parado, de sentado a parado, pararse sobre el pie izquierdo con o sin ayuda, balancear el pie izquierdo mientras están parados (Lozoff et al., 1987; Walter et al., 1989), bajar escalones con ayuda y caminar sobre una línea (Lozoff et al., 1987). También, se ha documentado en lactantes entre 9 y 10 meses de edad con ADFe, en contraste con aquellos con ENFeN, pobre control de las extremidades superiores, evaluado a través de cuatro medidas de alcance (duración/tiempo de alcance, velocidad máxima de la muñeca, número de unidades de movimiento y rectitud de la trayectoria de la mano), así como en 
dos de agarre (amplitud máxima de apertura y duración/tiempo desde la apertura hasta el primer contacto) (Shafir, Angulo-Barroso, Su, Jacobson y Lozoff, 2009).

Los lactantes con ADFe han manifestado ciertas características comportamentales propias y específicas que los describen como temerosos, indecisos (Lozoff et al., 1998), con menor afecto positivo (Lozoff et al., 2010) y menor placer en el juego libre, tanto en casa como en el laboratorio (Lozoff et al., 1998). No les gusta jugar más allá de un brazo de distancia de su madre (Lozoff et al., 1986, 1998), prestan menor atención a las instrucciones y demostraciones (Lozoff et al., 1998; Walter et al., 1989), se esfuerzan menos para contestar los reactivos durante las evaluaciones, no buscan la interacción social, son irritables, necesitan que los carguen constantemente y cuando se enojan o lloran no se calman fácilmente (Lozoff et al., 1998). En casa, exploran menos el ambiente, es más probable encontrarlos dormidos durante el día, o despiertos, pero acostados en la cama o jugando solos, que caminando en el patio o jugando con diferentes objetos (Lozoff et al., 1998). Dado que las madres de este tipo de niños muestran menor sensibilidad a las pistas sociales emitidas por ellos y menor número de comportamientos que fomenten el crecimiento social, emocional y cognitivo de sus hijos (Armony-Sivan, Kaplan-Estrin, Jacobson, y Lozoff, 2010), se ha explorado la hipótesis de "aislamiento funcional" en lactantes con ADFe. Ésta sostiene que la disminución en la actividad de los niños desnutridos los lleva a buscar menos estimulación de su entorno físico y social y, por consiguiente, en respuesta a esta conducta de los lactantes, los cuidadores tienden a ofrecer menor estimulación (Lozoff et al., 1998). Con el tiempo, estos patrones alterados de comportamiento, tanto del lactante como del cuidador, limitarían la interacción con el ambiente y afectarían negativamente su desarrollo.

\section{Efecto de la DFe Crónica durante la lactancia y del tratamiento correctivo y preventivo}

Al parecer, la DFe Crónica por más de dos meses durante la lactancia tiene un efecto adverso mayor que las dos condiciones anteriores sobre la ejecución de tareas relacionadas con la Escala Mental de Bayley (Lozoff et al., 1987; Lozoff, Wolf, y Jiménez, 1996; Walter et al., 1989), la motricidad (Angulo-Kinzler et al., 2002; Beltrán-Navarro et al., 2012; Lozoff et al., 1987, 1996; Stoltzfus et al., 2001; Walter et al., 1989) y el lenguaje (Beltrán-Navarro et al., 2012; Stoltzfus et al., 2001; Walter et al., 1989).

Existe controversia de si la suplementación con hierro en los lactantes con ADFe repercute positivamente en este desfase. La mayoría de los estudios señalan que esta disparidad continúa después de dos (Beltrán-Navarro et al., 2012), tres (Lozoff et al., 1987; Walter et al., 1989), seis (Lozoff et al., 1996) y 12 meses de tratamiento con hierro (Roncagliolo et al., 1998), aun cuando el estado nutricio se haya normalizado, mientras que la minoría de los artículos indican que la suplementación con hierro es suficiente para borrar esta diferencia (Akman et al., 2004; Idjradinata, y Pollitt, 1993). Además, el porcentaje de éxito del tratamiento es bajo ya que se ha señalado que solo de $36 \%$ (Lozoff et al., 1987) a $58 \%$ (Walter et al., 1989) de los lactantes con ADFe moderada corrigen completamente sus valores de hierro y hemoglobina después de tres meses de suplementación. Ante este panorama, se analizó la eficacia de estrategias preventivas administrando un suplemento de hierro desde la semana seis posnatal y hasta los nueve meses de edad, para reducir el efecto adverso de la DFe sobre el desarrollo; sin embargo, en este caso, más de $60 \%$ de los niños $(n=1276)$ presentaron DFe a la edad de nueve meses en la que terminaron el tratamiento. No obstante, la suplementación preventiva desde la etapa 
prenatal (semana 16), resultó eficaz cuando se continuó en la etapa posnatal y se suministró una mayor cantidad de hierro desde la semana seis y hasta los nueve meses después del nacimiento (Lozoff et al., 2016).

La heterogeneidad en los resultados permite plantear dos escenarios de cierta forma contradictorios: 1.- ausencia de un efecto positivo de la suplementación con hierro sugiere que la corrección de la $\mathrm{ADFe}$ es insuficiente para revertir el daño causado en el desarrollo; 2.- reversibilidad de los déficits en aspectos específicos: en el lenguaje y la motricidad después de 12 meses de tratamiento (Stoltzfus et al., 2001) y en la cognición y la motricidad después de tres (Akman et al., 2004) y cuatro meses (Idjradinata y Pollitt, 1993) de suplementación oral con hierro. No obstante, aún existe la duda de si la ineficacia del tratamiento es por lo inadecuado del tratamiento, por su extemporaneidad o bien, se relaciona con su interrupción o con la administración irregular de este, ya que por ejemplo, se ha reportado en México una alta incidencia de incumplimiento de tratamientos terapéuticos para diversas enfermedades (55.5 \% a $60 \%$ ), sobre todo ante enfermedades crónicas, tratamientos complejos, tratamientos de más de siete días y pacientes pediátricos (Reyes et al., 1998) como sería en este caso.

\section{Efecto a largo plazo de la DFe}

De acuerdo con la OMS (2001), cuando los lactantes con DFe llegan a la edad escolar, muestran un desfase en las pruebas relacionadas con el lenguaje, la motricidad y el desarrollo intelectual global, y se ubican de 5 a 10 puntos por debajo del promedio del cociente de inteligencia. La anterior aseveración se apoya en resultados de estudios longitudinales realizados en diversos países; por ejemplo, Chile (Walter et al., 1989), Costa Rica (Lozoff et al., 1987), Islandia (Gunnarsson, Thorsdottir, Palsson, y Gretarsson, 2007) y Francia (Dommergues et al., 1989). En específico, se ha reportado que los lactantes que presentaron
DFe sin-A (Gunnarsson et al., 2007) o ADFe (Dommergues et al., 1989; Lozoff et al., 1987; Walter et al., 1989) exhiben desventajas en el cociente general de desarrollo a la edad de dos (Dommergues et al., 1989) y cinco años edad (Lozoff, Jimenez y Wolf, 1991); en la actividad visomotora (Lozoff et al., 1991) a los cinco años de edad; en el desarrollo motor a la edad de cinco (Corapci, Radan y Lozoff, 2006) y seis años (Gunnarsson et al., 2007), y en el rendimiento escolar a la edad de 10 años (Rivera y Walter, 1996).

Respecto a la relación con su entorno, niños de cuatro años de edad que presentaron DFe crónica y que fue corregida hasta los 24 meses de edad, presentan menor afecto positivo, menor tolerancia a la frustración, mayor conducta pasiva y menor aceptación de un extraño (Chang et al., 2011). A los cinco años de edad, también se ha señalado menor afecto positivo y menor número de vocalizaciones durante las actividades realizadas, así como menor contacto ocular y menor afecto positivo en la interacción madre-hijo (Corapci et al., 2006). En la edad escolar, presentan menor desempeño en tareas de aritmética, lectura (Lozoff, Jimenez, Hagen, Mollen y Wolf, 2000), educación física y en el promedio general (Rivera y Walter, 1996). Su motricidad, memoria espacial y atención selectiva también se encuentran disminuidas; además, usualmente han repetido algún grado escolar, tienen mayor probabilidad de ser referidos a educación especial (Lozoff et al., 2000), mayor dependencia hacia el profesor y mayor frecuencia de solicitud de ayuda en trabajos escolares (Rivera y Walter, 1996). Entre los 11 y 14 años de edad, su comportamiento incluye un mayor número de conductas internalizantes o externalizantes (Corapci, Calatroni, Kaciroti, Jimenez y Lozoff, 2010), con manifestaciones de ansiedad, depresión, aislamiento, desajuste social y conductas delictivas y agresivas (Lozoff et al., 2000). El patrón de evolución de sus funciones motrices es lento y conservan el desfase con sus pares 
aún a la edad de 11 a14 años (Shafir et al., 2006). En específico, se señaló que, en la adolescencia, el haber presentado ADFe durante la lactancia, estaba relacionado con uso excesivo de alcohol y mayor presencia de conductas riesgosas, por ejemplo, las sexuales, y que eso era efecto de las pobres habilidades regulatorias presentadas durante la niñez (East et al., 2018). En la adultez temprana, el efecto de la DFe crónica durante la lactancia sigue observándose a través de un bajo desempeño en tareas relacionadas con el funcionamiento ejecutivo: control inhibitorio, respuesta al cambio, planeación $\mathrm{y}$ memoria de reconocimiento (Lukowski et al., 2010). A los 22 años de edad, mediante un estudio con resonancia magnética estructural, aquellos con ADFe durante la lactancia, mostraron diferencias en la activación de la red atencional en estado de reposo, involucrada en memoria, atención, cognición social y procesos de automonitoreo (Algarin et al., 2017). A la edad de 25 años, se ha registrado $76.1 \%$ de deserción escolar, acompañada de una pobre salud emocional caracterizada por emociones negativas y sentimientos de disociación/desprendimiento (Lozoff et al., 2013). Estas alteraciones se han relacionado con una afectación del sistema dopaminérgico (Lozoff et al., 2010; Lukowski et al., 2010), del hipocampo (Burden et al., 2007; Geng et al., 2015; Lukowski et al., 2010) y la interacción entre ambos (Lukowski et al., 2010).

En síntesis, las manifestaciones del efecto de la DFe en lactantes cambian de acuerdo con la edad; las repercusiones sensoriales, motoras y cognitivas observadas en edades tempranas se relacionan con fallas en el funcionamiento ejecutivo en la adultez. La tendencia a la internalización y pasividad se transforma en problemas socioemocionales. Estos perfiles incidirán negativamente en la vida social y laboral en un buen número de personas con DFe cuando lactantes. No obstante, la interacción entre variables biológicas y ambientales marca diferencias en el desarrollo de los lactantes que la padecen.

\section{Variables moduladoras}

Se sabe que la DFe está presente tanto en países industrializados como en países menos industrializados (WHO, 2015) y afecta a cualquier población sin respetar edad, raza o estrato social. Sin embargo, ocurre con mayor frecuencia en los estratos socioeconómicos más bajos (WHO, 2001). En la adultez temprana, se ha reportado que el estado socioeconómico bajo acrecienta el efecto de la DFe crónica presente durante la lactancia, ya que la brecha en el funcionamiento cognitivo entre pares con y sin DFe crónica en la etapa lactante es más amplia cuando adultos, en aquéllos de estrato socioeconómico bajo (Lozoff, Jimenez y Smith, 2006).

La pobreza y el contexto sociocultural desfavorable incrementan el riesgo a la ADFe (Walker et al., 2007). Se ha documentado el vínculo entre pobreza y DFe de una manera concatenada. El bajo desarrollo conlleva a un menor desempeño escolar, fatiga y baja productividad en el trabajo. Estos factores acarrean dificultades para mantener el empleo, y para obtener mayor entrenamiento y educación en otras áreas. Los bajos ingresos se traducen en dificultad para costear una dieta suficiente en hierro heme (carne, pollo y pescado); en consecuencia, tanto los adultos como los niños de la familia estarían expuestos a esta deficiencia nutrimental (Haas y Brownlie, 2001; Walker et al., 2007). Pollit et al. (1996) señalaron que se trata de una cadena de eventos que conlleva a una situación de desventaja; los cambios estructurales y bioquímicos pueden alterar la función cerebral y disminuir la capacidad para aprender, la cual disminuye la exposición y respuesta a estímulos ambientales y por tanto limita el desarrollo. Además, los cambios en el comportamiento y afectividad del lactante pueden entorpecer el proceso de aprendizaje. Asimismo, diversos estudios que reportaron efecto de la ADFe sobre el desarrollo en lactantes, también encontraron una asociación entre esta deficiencia nutrimental y las características intelectuales (menor cociente 
intelectual: Lozoff et al., 1987) y educativas (menos años de estudio: Idjradinata y Pollitt, 1993; Lozoff et al., 1996; Walter et al., 1989) de sus madres. En la Tabla 1 se presenta un resumen sobre los efectos neuropsicológicos de la DFe.

Tabla 1. Estudios analizados sobre el efecto de la DFe sobre el desarrollo neuropsicológico en muestras con edades comprendidas entre el nacimiento y los 25 años.

\begin{tabular}{|c|c|c|}
\hline \multicolumn{2}{|r|}{ Referencia } & Dominios afectados \\
\hline 1 & $\begin{array}{l}\text { Akman et al. } \\
\text { (2004) Turquía }\end{array}$ & $\begin{array}{c}\text { Pretratamiento: ADFe y DFe sin-A, índices de Desarrollo Mental y } \\
\text { Motor. Postratamiento: Ninguno. }\end{array}$ \\
\hline 2 & $\begin{array}{l}\text { Algarín et al. } \\
\text { (2017) Chile }\end{array}$ & Memoria, atención, procesos de automonitoreo y cognición social. \\
\hline 3 & $\begin{array}{l}\text { Armony-Sivan et } \\
\text { al. (2016) China }\end{array}$ & Aislamiento y emociones negativas. \\
\hline 4 & $\begin{array}{l}\text { Baptista-González } \\
\text { et al. (2004) } \\
\text { México }\end{array}$ & $\begin{array}{l}\text { A mayor severidad de la DFe sin-A, menor puntaje en el índice de } \\
\text { desarrollo motor. }\end{array}$ \\
\hline 5 & $\begin{array}{l}\text { Beltrán-Navarro et } \\
\text { al. (2012) México }\end{array}$ & $\begin{array}{l}\text { DFe crónica: índice de desarrollo motor de Bayley, percepción de sonidos } \\
\text { ambientales, lenguaje receptivo, lenguaje expresivo y motricidad gruesa. }\end{array}$ \\
\hline 6 & $\begin{array}{l}\text { Burden et al. } \\
(2007) \text { USA }\end{array}$ & ADFe: atención y memoria de reconocimiento. \\
\hline 7 & $\begin{array}{l}\text { Carter et al. } \\
\quad(2010) \\
\text { USA }\end{array}$ & $\begin{array}{l}\text { Pretratamiento: ADFe, permanencia del objeto, memoria de } \\
\text { reconocimiento. } \\
\text { Postratamiento: Ninguno. }\end{array}$ \\
\hline 8 & $\begin{array}{l}\text { Chang et al. } \\
\text { (2011) } \\
\text { China }\end{array}$ & $\begin{array}{l}\text { DFe crónica: menor afecto positivo, menor tolerancia a la frustración y } \\
\text { mayor pasividad. }\end{array}$ \\
\hline 9 & $\begin{array}{l}\text { Corapci et al. } \\
\text { (2010) Costa Rica }\end{array}$ & Mayor número de conductas internalizantes y externalizantes. \\
\hline 10 & $\begin{array}{l}\text { Corapci et al. } \\
\qquad(2006) \\
\text { Costa Rica }\end{array}$ & $\begin{array}{l}\text { DFe crónica: menor actividad física, menor afecto positivo y menor } \\
\text { verbalización, menor contacto visual, menor espera de turnos y menor } \\
\text { afecto positivo. }\end{array}$ \\
\hline 11 & $\begin{array}{l}\text { Deinard et al. } \\
\text { (1981)USA }\end{array}$ & $\begin{array}{l}\text { DFe severa: diferencias en el reactivo de la escala comportamental de } \\
\text { Bayley sobre se muestra más temeroso ante nuevas personas o nuevas } \\
\text { situaciones. }\end{array}$ \\
\hline 12 & $\begin{array}{l}\text { Dommergues et } \\
\text { al. (1989) Francia }\end{array}$ & $\begin{array}{l}\text { A los dos años de edad, asociación entre la concentración de hemoglobina } \\
\text { con el cociente de desarrollo, el cociente motor y el cociente social. }\end{array}$ \\
\hline 13 & $\begin{array}{l}\text { East et al. (2018) } \\
\qquad \text { Chile }\end{array}$ & $\begin{array}{l}\text { ADFe: entre los 14-17 años, menor autocontrol, mayor número de } \\
\text { conductas de riesgo (ej.: consumo de alcohol y comportamiento sexual). }\end{array}$ \\
\hline 14 & $\begin{array}{l}\text { Geng et al. (2015) } \\
\text { China }\end{array}$ & DFe sin-A: memoria de reconocimiento. \\
\hline 15 & $\begin{array}{l}\text { Gunnarson et al. } \\
\text { (2007) Islandia }\end{array}$ & DFe sin-A y depleción de Fe: motricidad fina a los seis años de edad. \\
\hline
\end{tabular}


Referencia

Dominios afectados

\begin{tabular}{|c|c|c|}
\hline 16 & $\begin{array}{l}\text { Hernández- } \\
\text { Martínez et al. } \\
\text { (2011) España }\end{array}$ & $\begin{array}{l}\text { Neonatos de madres con DFe sin-A en primer y segundo trimestre de } \\
\text { gestación: alterada respuesta autónoma. } \\
\text { Neonatos de madres con DFe sin-A en tercer trimestre de gestación: } \\
\text { comportamiento motor y autorregulación. }\end{array}$ \\
\hline 17 & $\begin{array}{l}\text { Idjradinata y } \\
\text { Pollitt (1993) } \\
\text { Indonesia } \\
\end{array}$ & $\begin{array}{l}\text { Pretratamiento: ADFe, índice de desarrollo mental y motor. } \\
\text { Postratamiento: ninguno. }\end{array}$ \\
\hline 18 & $\begin{array}{l}\text { Kariger et al. } \\
(2005) \text { Zanzibar }\end{array}$ & $\begin{array}{c}\text { En los dos grupos, } 82.6 \text { y } 83.9 \% \text { presentaban DFe y/o anemia. Lactantes } \\
\text { sin DFe tenían } 66 \% \text { de caminar que aquéllos con DFe con o sin-A. }\end{array}$ \\
\hline 19 & $\begin{array}{l}\text { Lozoff et al. } \\
\qquad(1987) \\
\text { Costa Rica }\end{array}$ & $\begin{array}{c}\text { Pretratamiento: ADFe, índice de desarrollo mental y motor. } \\
\text { Postratamiento } 7 \text { días: ADFe, índice de desarrollo mental y motor. } \\
\text { Postratamiento } 3 \text { meses: en } 64 \% \text { del grupo con ADFe, índice de } \\
\text { desarrollo mental y motor. }\end{array}$ \\
\hline 20 & $\begin{array}{l}\text { Lozoff et al. } \\
\text { (2008)USA }\end{array}$ & $\begin{array}{l}\text { ADFe y DFe sin-A: mayor timidez, más tiempo para calmarse cuando se } \\
\text { enojaban, menor afecto positivo y fallas en la orientación hacia el juego. }\end{array}$ \\
\hline 21 & $\begin{array}{l}\text { Lozoff et al. } \\
\qquad(2000) \\
\text { Costa Rica }\end{array}$ & $\begin{array}{c}\text { DFe crónica en la lactancia: aritmética, expresión escrita, motricidad, } \\
\text { memoria espacial, recuerdo selectivo. Mayor reporte de padres y } \\
\text { maestros de comportamientos de ansiedad/depresión, problemas sociales } \\
\text { y atencionales. }\end{array}$ \\
\hline 22 & $\begin{array}{l}\text { Lozoff et al. } \\
\qquad(2006) \\
\text { Costa Rica }\end{array}$ & $\begin{array}{l}\text { DFe crónica en la lactancia: el estado socioeconómico moderó el } \\
\text { efecto de la DFe crónica: bajo nivel socioeconómico mayor brecha } \\
\text { en su desempeño cognitivo (10-25 puntos por debajo de la media de } \\
\text { inteligencia esperada) en comparación con clase media (8-9 puntos por } \\
\text { debajo de lo esperado). }\end{array}$ \\
\hline 23 & $\begin{array}{l}\text { Lozoff et al. } \\
\text { (1991) Costa Rica }\end{array}$ & $\begin{array}{c}\text { DFe crónica en la lactancia: cociente de Inteligencia, motricidad, } \\
\text { habilidades visoespaciales y habilidades académicas. }\end{array}$ \\
\hline 24 & $\begin{array}{l}\text { Lozoff et al. } \\
\text { (1998) } \\
\text { Costa Rica }\end{array}$ & $\begin{array}{l}\text { ADFe: permanecían cerca de los cuidadores durante la sesión, menos } \\
\text { activos físicamente, exploraban menos el ambiente, menos placer en las } \\
\text { actividades, más temerosos, indecisos, se cansaban rápido, pocos intentos } \\
\text { para contestar los reactivos, menos atención a las instrucciones y jugaban } \\
\text { menos. Sus cuidadores, iniciaban más frecuentemente la interacción que } \\
\text { los demás cuidadores, pero se reían menos, mostraban menos placer } \\
\text { en las actividades realizadas por el lactante y menos probable que los } \\
\text { animaran verbalmente. En las visitas a los hogares, los lactantes estaban } \\
\text { irritables, sin hacer nada, acostados, dormidos, o siendo cargados. }\end{array}$ \\
\hline 25 & $\begin{array}{l}\text { Lozoff et al. } \\
\text { (1986) Guatemala }\end{array}$ & Los lactantes con ADFe buscaban más contacto corporal con su madre. \\
\hline 26 & $\begin{array}{l}\text { Lozoff et al. } \\
\text { (2010) Chile }\end{array}$ & $\begin{array}{c}\text { Pretratamiento: ADFe, menor afecto positivo. } \\
\text { Postratamiento: ADFe, grupo de intervención: mejora del } \\
\text { aspecto socioemocional sin igualarse al grupo ENFeN. Grupo de } \\
\text { observación semanal: menor incremento en sus puntajes cognitivos y } \\
\text { socioemocionales. }\end{array}$ \\
\hline 27 & $\begin{array}{l}\text { Lozoff et al. } \\
\qquad(2013) \\
\text { Costa Rica }\end{array}$ & $\begin{array}{c}\text { DFe crónica en la lactancia: mayor deserción escolar menor vínculo } \\
\text { afectivo; pobre salud emocional; mayor número de sentimientos } \\
\text { negativos y sentimientos de desapego. }\end{array}$ \\
\hline
\end{tabular}


Referencia

Dominios afectados

\begin{tabular}{|c|c|c|}
\hline 28 & $\begin{array}{c}\text { Lozoff et al. } \\
\text { (1982) Guatemala }\end{array}$ & $\begin{array}{c}\text { Diferencias significativas en las puntuaciones de la escala mental de los } \\
\text { lactantes con ADFe de } 19 \text { a } 24 \text { meses de edad. }\end{array}$ \\
\hline 29 & $\begin{array}{l}\text { Lozoff et al. } \\
\qquad(1996) \\
\text { Costa Rica }\end{array}$ & $\begin{array}{l}\text { Pretratamiento: ADFe, índice de desarrollo mental de Bayley. } \\
\text { Postratamiento } 3 \text { y } 6 \text { meses: ADFe, índice de desarrollo mental de Bayley. }\end{array}$ \\
\hline 30 & $\begin{array}{l}\text { Lukowski et al. } \\
\text { (2010) Costa Rica }\end{array}$ & $\begin{array}{l}\text { DFe crónica en la lactancia: control inhibitorio, planeación, adaptación y } \\
\text { memoria de reconocimiento. }\end{array}$ \\
\hline 31 & $\begin{array}{l}\text { Olney et al. (2007) } \\
\text { Tanzania }\end{array}$ & $\begin{array}{l}\text { Se encontró ADFe en: } 98 \text { lactantes del grupo que no se mueve, } 79 \text { en el } \\
\text { de lactantes que gatean y } 195 \text { en el de lactantes que caminan. } \\
\text { En todos los grupos la DFe con y sin-A fue predictor de menor actividad } \\
\text { motora y de bajo desempeño locomotor. }\end{array}$ \\
\hline 32 & $\begin{array}{l}\text { Rivera y Walter } \\
\text { (1996) } \\
\text { Chile }\end{array}$ & $\begin{array}{c}\text { ADFe en la lactancia: lenguaje escrito, lectura, dictado, resolución de } \\
\text { problemas aritméticos, tiempo de reacción más amplio en las tareas } \\
\text { motoras, más dependientes en la aprobación del profesor y solicitud con } \\
\text { mayor frecuencia ayuda en actividades escolares. }\end{array}$ \\
\hline 33 & $\begin{array}{l}\text { Santos et al. } \\
\text { (2018) } \\
\text { China }\end{array}$ & $\begin{array}{l}\text { a) DFe fetal-neonatal, y b) DFe fetal-neonatal-y a los } 9 \text { meses de edad: } \\
\text { menores puntajes en tareas de locomoción. } \\
\text { Aquéllos del segundo grupo, también exhibieron menor desempeño en } \\
\text { reactivos involucrados con motricidad gruesa. } \\
\text { La severidad de DFe materna en el tercer trimestre de gestación se } \\
\text { asoció con menores puntajes de desarrollo motor y comportamientos } \\
\text { vestibulares. }\end{array}$ \\
\hline 34 & $\begin{array}{c}\text { Shafir et al. (2006) } \\
\text { Costa Rica }\end{array}$ & $\begin{array}{c}\text { DFe crónica en la lactancia: menor desempeño motor en las tres } \\
\text { evaluaciones realizadas. Tratamiento con Fe corrigió la DFe, pero no } \\
\text { hubo evidencia de recuperación en el desarrollo motor. }\end{array}$ \\
\hline 35 & $\begin{array}{l}\text { Shafir et al. (2008) } \\
\text { USA }\end{array}$ & ADFe y DFe sin-A: motricidad. \\
\hline 36 & $\begin{array}{l}\text { Shafir et al. (2009) } \\
\text { USA }\end{array}$ & ADFe: motricidad fina y gruesa. \\
\hline 37 & $\begin{array}{l}\text { Stoltzfus et al. } \\
\qquad(2001) \\
\text { Tanzania }\end{array}$ & $\begin{array}{l}97 \% \text { de los niños presentaban anemia, la cual se atribuyó a la DFe. } \\
\text { Tratamiento oral con Fe mejoró el desempeño de lenguaje. El desempeño } \\
\text { motor también mejoró después del tratamiento, pero sólo en los niños con } \\
\text { concentraciones de hemoglobina }<90 \mathrm{~g} / \mathrm{l} \text {. }\end{array}$ \\
\hline 38 & $\begin{array}{l}\text { Tamura et al. } \\
\text { (2002) USA }\end{array}$ & $\begin{array}{l}\text { Asociación entre el estado nutricio de Fe neonatal y bajo desempeño } \\
\text { mental y psicomotor a los cinco años de edad. }\end{array}$ \\
\hline 39 & $\begin{array}{l}\text { Walter et al. } \\
\text { (1989) } \\
\text { Chile }\end{array}$ & $\begin{array}{c}\text { Pretratamiento: ADFe, índice de desarrollo mental y motor y } \\
\text { comportamental. } \\
\text { Postratamiento } 10 \text { días y } 3 \text { meses: ADFe, índice de desarrollo mental y } \\
\text { motor. }\end{array}$ \\
\hline
\end{tabular}

El superíndice corresponde al número consecutivo del artículo.

Pruebas:_Escala Mental Infantil de Bayley ${ }^{1,45,511,17,19,28,29,39}$, Escala Motora Infantil de Bayley $1,4,5,11,17,19,24,26,28,29,34,39$, Escala Comportamental Infantil de Bayley $y^{5,711,24,26,29,35,39}$, Prueba de Desarrollo de Denver ${ }^{1}$, Escala de Lenguaje Preescolar ${ }^{5}$, Prueba de Inteligencia Infantil de Fagan ${ }^{7}$, Escala de desarrollo de Uzgiris y Hunter ${ }^{11}$, Escala Brunet-Lezine ${ }^{12}$, Perfil de 
Salud y Enfermedad Infantil-Adolescentes ${ }^{13}$, Inventario de Uso de Alcohol $^{13}$, Escala de Evaluación de Ajuste Social ${ }^{13}$, Escala HOME ${ }^{13,32}$, Inventario de Desarrollo de Islandia ${ }^{15}$, Escala de Desarrollo Neonatal de Brazelton ${ }^{16}$, Escala de 14 logros motores de la $\mathrm{OMS}^{18}$, Logros del desarrollo motor ${ }^{35}$, Cuestionario sobre Temperamento ${ }^{7,20}$, Escala Wechsler de Inteligencia para Niños-WISC ${ }^{21,23,38}$, Escala Wechsler de Inteligencia para Adultos-WAIS ${ }^{22}$, Prueba de Logros de Amplio Rango ${ }^{21}$, Prueba Gestalt Visomotora de Bender ${ }^{21}$, Prueba Motora de Bruininks-Oseretsky ${ }^{21,23,32,34}$, Prueba de Recuerdo Serial ${ }^{21}$, Prueba de Capacidad Atencional ${ }^{21}$, Memoria Espacial de la Prueba K-ABC ${ }^{21}$, Prueba de Subrayado $^{21}$, Pruebas de Habilidades Cognitivas ${ }^{21}$, Logro Aritmético ${ }^{22}$, Prueba Psicoeducativa de Woodcock-Johnson ${ }^{23,32}$, Prueba de Integración Visomotora de Beery ${ }^{23,32}$, Figura Humana de Goodenough-Harris ${ }^{23}$, Trail Making Test ${ }^{30}$, Batería de evaluación Neuropsicológica Automatizada de Cambridge ${ }^{30}$, Prueba de Evaluación Motora ${ }^{30}$, Escala de Terman y Merrill $^{132}$, Escala Motora de Peabody ${ }^{33,35,38}$, Batería Internacional Neurológica Infanti1 ${ }^{33,35}$, Escala McCarthy de desarrollo infantil ${ }^{37}$, Prueba Griffith ${ }^{37}$, Prueba de comprensión del lenguaje ${ }^{38}$, Inventario de Yale de atención y tratabilidad ${ }^{38}$. Cuestionarios: Cuestionario de Comportamiento de Achenbach ${ }^{9,13,21,32}$, Cuestionario sobre Estatus de Logros Educativos $^{27}$, Cuestionario sobre el Monitoreo del Futuro ${ }^{27}$, Encuesta de Salud para Adultos y Jóvenes ${ }^{27}$, Inventario de Depresión de Beck ${ }^{27}$, Escala de Ansiedad ${ }^{27}$, Escala de Reajuste Social ${ }^{27}$, Escala de Autoestima de Piers-Harri ${ }^{32}$, Guía de Rendimiento y Comportamiento Escolar ${ }^{32}$.

Tareas: Peek-a-boo ${ }^{3}$, Aparición de persona extraña ${ }^{3}$. Percepción de sonidos ambientales, Discriminación de estímulos familiares ${ }^{6}$, A no B ${ }^{7}$, Discriminación de la voz de la madre ${ }^{14}$, Escritura Dirigida ${ }^{21}$, Rendimiento Táctico, Tiempo de Reacción $^{30}$, Memoria operativa ${ }^{30}$, Velocidad de denominación ${ }^{30}$, Memoria de reconocimiento $^{30}$, Incompatibilidad estímulo-respuesta $^{30}$, Recuperación de un juguete ${ }^{35}$, Alcance y agarre de la mano ${ }^{36}$.

Observaciones libres: Juego libre ${ }^{8,24,25}$, Interacción madre-hijo ${ }^{10}$, Observación en casa ${ }^{24}$, Observación de dos horas de actividad motora en casa ${ }^{31}$.

\section{Evidencias concomitantes de estudios con medidas electrofisiológicas}

Los hallazgos reportados en los apartados anteriores son apoyados con los propios de estudios que involucran medidas neurofisiológicas que muestran mayor latencia de conducción central, medida a través de potenciales evocados auditivos, en neonatos con DFe sin-A que en aquellos con ENFeN (Amin, Orlando y Wang, 2013) y mayor tiempo de conducción central en la respuesta auditiva del tallo cerebral a los 3 y 10 meses de edad en lactantes con baja concentración de ferritina al nacimiento y anemia a los 10 meses de edad, en contraste con niños con ENFeN (Lou et al., 2016). El tiempo de conducción central se considera como un índice de desarrollo del SNC, pues la mielinización y la maduración de las vías sinápticas reducen la latencia de transmisión de información.

Sobre las emociones, Armony-Sivan et al. (2016), mediante la evaluación con electroencefalograma, encontraron asimetría frontal derecha, un correlato neural que se ha asociado a comportamientos relacionados con aislamiento y emociones negativas, en lactantes de nueve meses de edad con antecedentes de DFe prenatal y DFe posnatal, al cotejarlos con niños que pertenecían a los grupos de solo DFe prenatal o solo DFe posnatal y aquellos que no presentaron DFe. Según los autores eso podría deberse al efecto de la DFe sobre diversos sistemas de neurotransmisión, específicamente, dopamina, serotonina y norepinefrina.

En la ADFe, también se ha reportado mayor tiempo de conducción central, a través de potenciales evocados auditivos, en lactantes de 6 meses de edad con ADFe en comparación con lactantes sin anemia y que esta diferencia se acentuaba a los 12, 18 (Roncagliolo et al., 1998) y 48 meses de edad (Algarín, Peirano, Garrido, Pizarro y Lozoff, 2003), aun cuando se hubiera corregido esta deficiencia nutrimental con tratamiento oral con hierro. Este resultado está en consonancia con lo observado mediante potenciales evocados visuales, es decir, mayor latencia de transmisión en participantes de entre 6y 24 meses (Monga, 
Walia, Gandhi, Chandra y Sharma, 2010) y 48 meses de edad (Algarín et al., 2003) con ADFe. También, se ha argumentado que los patrones alterados de husos de sueño encontrados en niños con ADFe a la edad de 6meses, evidencian un retraso madurativo en diversos procesos relacionados con el SNC, tales como la mielinización, el crecimiento dendrítico y diversos sistemas de neurotransmisión como la dopamina, serotonina y norepinefrina, lo que podría impactar diversas habilidades cognitivas, entre ellas la memoria (Peirano, Algarín, Garrido y Lozoff, 2007).

De igual forma, se ha reportado un efecto de la DFe crónica en la latencia de conducción central auditiva (Roncagliolo et al., 1998) y los patrones de sueño (Peirano, Algarín, Garrido, Algarín y Lozoff, 2007). A largo plazo, los lactantes con antecedentes de ADFe (Roncagliolo et al., 1998) manifestaron, a los cuatro años de edad, periodos de sueño más largos junto con mayor movimiento de piernas al estar dormidos (Angulo-Barroso et al., 2013), la distribución de los episodios MOR -movimientos oculares rápidos- y sus características (menor latencia) también resultaron anómalas, mostrando patrones de sueño semejantes a los observados en pacientes depresivos (Peirano et al., 2007).

\section{Evidencias conexas de estudios con roedores}

Resultados de estudios realizados con roedores ponen en evidencia que la interrupción temprana en el desarrollo del procesamiento, almacenamiento o disponibilidad del hierro, afecta tanto la cantidad como la calidad de la mielina y que la composición y la cantidad de ésta siguen alteradas, aun cuando el contenido de hierro de la mielina alcanza los niveles esperados después del consumo de dieta suplementada (Ortiz et al., 2004). A nivel metabólico, Kwik-Uribe, Gietzen, German, Golub y Keen (2000) demuestran que la DFe durante el desarrollo temprano, además de producir cambios marcados en la concentración de hierro cerebral, resulta en interrup- ciones significativas en el metabolismo de la dopamina y en la composición de ácidos grasos de la mielina y, aunque se observe un aumento en la concentración de hierro en el cerebro después del consumo posnatal de dieta fortificada, algunas de las consecuencias bioquímicas no son completamente revertidas. De hecho, Morath y Mayer-Pröschel (2002) señalan que la irreversibilidad de algunos defectos causados por la falta de hierro en roedores podría ser una consecuencia de la interrupción del desarrollo de células precursoras (glioblastos) de oligodendrocitos. Dado que estas nacen durante una fase específica de desarrollo, es posible que una suplementación con hierro que se realice después de este periodo crítico sea extemporánea para restablecer o reparar cualquier interrupción que se haya producido.

A nivel de estructuras cerebrales específicas, la DFe perinatal produce modificaciones neuroquímicas en diversos metabolitos del hipocampo (Rao et al., 2003), lo que sugiere cambios persistentes en el estado energético de reposo, neurotransmisión y mielinización de esta región. Por su parte, Jorgenson et al. (2003) observaron un crecimiento dendrítico apical alterado específicamente dentro de las neuronas piramidales CA1 del hipocampo después de DFe gestacional y neonatal. La morfología atípica persistió en la adultez, aun cuando se normalizó la concentración de hierro. Cabe señalar que, para el establecimiento de nuevos recuerdos, las neuronas de CA1 reciben información de las de CA3 (colateral de Schaffer), y posteriormente la envían a neuronas del subículo (principal zona eferente del hipocampo), quienes sinaptarán con regiones como el hipotálamo, corteza prefrontal, amígdala, entre otras (Moorthi, Premkumar, Priyanka, Jayachandran y Anusuyadevi, 2015). En síntesis, el efecto de la DFe sobre la morfología dendrítica durante este periodo de rápido desarrollo produciría cambios duraderos en la propagación del mensaje dendrítico y la posterior eficacia sináptica dentro del hipocampo, lo que conlle- 
varía a fallas en la memoria y el aprendizaje (Jorgenson et al., 2003). Otras estructuras cerebrales que se han analizado a través de modelos animales son el cuerpo estriado, la corteza prefrontal y el mesencéfalo; Beard et al. (2002) señalaron que la DFe temprana ocasionó tanto disminución significativa en el contenido de hierro como empobrecimiento en los receptores y transportadores de dopamina cerebral en estas estructuras. Aunado a lo anterior, observaron en estos roedores comportamientos que denotaban ansiedad. Estos hallazgos concuerdan con lo reportado por Li et al. (2011), quienes manifestaron que la alteración de la señalización dopaminérgica en la corteza prefrontal contribuye, probablemente, al comportamiento ansioso observado en ratas jóvenes con DFe severa. Se plantea que, en humanos, la patología prenatal de origen nutricio ocasiona una modificación de la trayectoria esperada de desarrollo, como, por ejemplo, en procesos involucrados con la mielinización, morfología dendrítica, sinapsis, desarrollo hipocampal, así como de otras estructuras cerebrales, y funcionamiento de diversos neurotransmisores.

\section{Conclusiones}

El hierro está implicado en diferentes mecanismos de desarrollo cerebral. Particularmente, la DFe sin-A y ADFe afectan estos mecanismos de manera regional, impactando aquellas áreas cerebrales que se encuentren en rápido desarrollo en el momento en que se presenta la deficiencia, ya que el SNC es más vulnerable a las deficiencias nutrimentales en periodos de mayor cambio: la gestación y los primeros dos años de vida. La afectación de estos procesos de maduración cerebral por agresiones ambientales, como son la DFe sin-A y ADFe, en este periodo crítico pueden tener efecto duradero sobre la estructura y funcionamiento cerebral. No obstante, la expresión de este efecto varía con la edad, $\mathrm{y}$ en edades avanzadas puede observarse en funciones más complejas, tales como la abstracción, el manejo simbólico y el funcionamiento ejecutivo. Asimismo, la interacción entre factores ambientales y biológicos contribuye en la expresión de este efecto adverso. La detección temprana de los efectos que ocasiona la DFe en los diferentes dominios cognitivos, lingüísticos, motores y comportamentales del lactante, facilitaría el diseño de programas de intervención que redunden en un efecto positivo en el desarrollo en las etapas ulteriores de la vida.

Finalmente, se sugiere que, dado que la anemia también puede ocurrir en consonancia con otras patologías diferentes a la DFe (deficiencias de folatos, vitamina A y B12, infecciones agudas y crónicas como la malaria, cáncer, tuberculosis y trastornos heredados o adquiridos que afectan la síntesis de hemoglobina, la producción o supervivencia de glóbulos rojos), sería importante hacer una revisión que analizara el efecto de la anemia como entidad clínica.

\section{Referencias bibliográficas}

Akman, M., Cebeci, D., Okur, V., Angin, H., Abali, O. y Akman, A. (2004). The effects of iron deficiency on infants' developmental test performance. Acta Paediatrica, 93, 1391-1396. doi: 10.1111/j.1651-2227.2004.tb02941.x

Algarín, C., Peirano, P., Garrido, M., Pizarro, F. y Lozoff, B. (2003). Iron deficiency anemia in infancy: Long-lasting effects on auditory and visual system functioning. Pediatric Research, 53(2), 217-223. doi: 10.1203/01. PDR.0000047657.23156.55

Algarín, C., Karunakaran, K., Reyes, S., Morales, C., Lozoff, B., Peirano, P. y Biswal, B. (2017). Differences on brain connectivity in adulthood are present in subjects with iron deficiency anemia in infancy. Frontiers in Aging Neuroscience, 9, 54. doi: 10.3389/fnagi.2017.00054

Amin, S., Orlando, M. y Wang, H. (2013). Latent iron deficiency in utero is associated with abnormal auditory neural myelination in $\geq 35$ weeks gestational age infants. The Journal of Pediatrics, 163(5), 1267-1271. doi: 10.1016/j.jpeds.2013.06.020 
Angulo-Kinzler, R., Peirano, P., Lin, E., Garrido, M. y Lozoff, B. (2002). Spontaneous motor activity in human infants with iron-deficiency anemia.Early Human Development, 66(2), 67-79. doi: 10.1016/S0378-3782(01)00238-9

Angulo-Barroso, R., Peirano, P., Algarin, C., Kaciroti, N., Lozoff, B., Algarín, C., ...Lozoff, B. (2013). Motor Activity and intra-individual variability according to sleep-wake states in preschool-aged children with iron-deficiency anemia in infancy. Early Human Development, 89(12), 1025-1031. doi: 10.1016/j.earlhumdev.2013.08.014

Antonides, A., Schoonderwoerd, A., Scholz, G., Berg, B., Nordquist, R. y van der Staay, F. (2015). Pre-weaning dietary iron deficiency impairs spatial learning and memory in the cognitive holeboard task in piglets. Frontiersin Behavioral Neuroscience, 9, 291. doi: 10.3389/ fnbeh.2015.00291

Armony-Sivan, R., Kaplan-Estrin, M., Jacobson, S. y Lozoff, B. (2010). Iron-deficiency anemia in infancy and mother-infant interaction during feeding. Journalof Developmental and Behavioral Pediatrics, 31(4), 326-332. doi: 10.1097/ DBP.0b013e3181dc525d

Armony-Sivan, R., Zhu, B., Clark, K., Richards, B., Ji, C., Kaciroti, N., ... Lozoff, B. (2016). Iron deficiency (ID) at both birth and 9 months predicts right frontal EEG asymmetry in infancy. Developmental Psychobiology, 58(4), 462-470. doi: 10.1002/dev.21388

Baptista-González, H., Barrera-Reyes, R., Rosenfeld-Mann, F., Ramírez-Maya, A. y Jiménez-Quiroz, R. (2004). Diferencias en el crecimiento y neurodesarrollo en el lactante menor deficiente de hierro no anémico. Boletín Médico del Hospital Infantil de México, 61, 9-18.

Barañano, D., Wolosker, H., Byoung-Il, B., Barrow, R., Snyder, S. y Ferrist, C. (2000). A mammalian iron ATPase induced by iron. The Journal of Biological Chemistry, 275(20), 15166-15173. doi: 10.1074/jbc.275.20.15166

Bayley, N. (1993). Bayley scales of infant development. San Antonio: The Psychological Corporation.

Beard, J., Erikson, K. y Jones, B. (2002).
Neurobehavioral analysis of developmental iron deficiency in rats. Behavioral Brain Research, 134, 517-524. doi: 10.1016/S01664328(02)00092-X

Beard, J., Erikson, K. y Jones, B. (2003). Neonatal iron deficiency results in irreversible changes in dopamine function in rats. The Journal of Nutrition, 133, 1174-1179. doi: 10.1093/ jn/133.4.1174

Beard, J., Wiesinger, J. y Connor, J. (2003). Pre- and postweaning iron deficiency alters myelination in Sprague-Dawley rats. Developmental Neuroscience, 25, 308-315. doi: 10.1159/000073507

Beltrán-Navarro, B., Matute, E., Vásquez-Garibay, E. y Zarabozo, D. (2012). Effect of chronic iron deficiency on neuropsychological domains in infants. Journal of Child Neurology, 27(3), 297-303. doi: 10.1177/0883073811416867

Burden, M., Westerlund, A., Armony-Sivan, R., Nelson, C., Jacobson, S., Lozoff, B., ... Jacobson, J. (2007). An event-related potential study of attention and recognition memory in infants with iron-deficiency anemia. Pediatrics, 120(2), 336-345. doi: 10.1542/peds.2006-2525

Burhans, M., Dailey, C., Beard, Z., Wiesinger, J., Murray-Kolb, L., Jones, B. y Beard, J. (2005). Iron deficiency: differential effects on monoamine transporters. Nutritional Neuroscience, 8 , 31-38. doi: 10.1080/10284150500047070

Carter, R., Jacobson, J., Burden, M., ArmonySivan, R., Dodge, N., Angelilli, M., ... Jacobson, S. (2010). Iron deficiency anemia and cognitive function in infancy. Pediatrics, 126(2), 427-434.doi: 10.1542/peds.2009-2097

Chang, S., Wang, L., Wang, Y., Brouwer, I., Kok, F., Lozoff, B. y Chen, C. (2011). Iron-deficiency anemia in infancy and social emotional development in preschool-aged Chinese children. Pediatrics, 127(4), 927-933. doi: 10.1542/peds.2010-1659

Corapci, F., Radan, A. y Lozoff, B. (2006). Iron deficiency in infancy and mother-child interaction at 5 years. Journal of Developmental and Behavioral Pediatrics, 27(5), 371-378. doi: 10.1097/00004703-200610000-00001

Corapci, F., Calatroni, A., Kaciroti, N., Jimenez, 
E. y Lozoff, B. (2010). Longitudinal evaluation of externalizing and internalizing behavior problems following iron deficiency in infancy. Journal of Pediatric Psychology, 35(3), 296-305. doi: 10.1093/jpepsy/jsp065

Deboer, T., Wewerka, S., Bauer, P., Georgieff, M. y Nelson, C. (2005). Explicit memory performance in infants of diabetic mothers at 1 year of age. Developmental Medicine \& Child Neurology, 47(8), 525-531. doi: 10.1111/ j.1469-8749.2005.tb01186.x

Deinard, A., Gilbert, A., Dodds, M. y Egeland, B. (1981). Iron deficiency and behavioral deficits. Pediatrics, 68, 828-833.

Dommergues, J., Archambeaud, B., Ducot, Y., Gerval, Y., Hiard, C., Rossignol, C. y Tchernia, G. (1989). Iron deficiency and psychomotor development scores: a longitudinal study between ages 10 months and 4 years. Archives Francaises de Pédiatrie, 46, 487-490.

East, P., Delker, E., Lozoff, B., Delva, J., Castillo, M. y Gahagan, S. (2018).Associations among infant iron deficiency, childhood emotion and attention regulation, and adolescent problem behaviors. Child Development, 89(2), 593-568. doi: 10.1111/cdev.12765

Ellison, P. (1994). The INFANIB. A reliable method for the neuromotor assessment of infants. San Antonio: Therapy Skill Builders.

Fenson, L., Bates, E., Dale, P., Goodman, J., Reznick, J. y Thal, D. (2000). Reply: measuring variability in early child language: don't shoot the messenger. Child Development, 71(2), 323-328.doi: 10.1111/1467-8624.00147

Folio, M. y Fewell, R. (2000). Peabody developmental motor scale. Second ed. Austin: Pro-Ed.

Frankenburg, W. y Dodds, J. (1992). Denver II training manual. Denver, Colorado: Denver Developmental Material Inc.

Geng, F., Mai, X., Zhan, J., Xu, L., Zhao, Z., Georgieff, M., ... Lozoff, B. (2015). Impact of fetal-neonatal iron deficiency on recognition memory at 2 months of age. The Journal of Pediatrics, 167(6), 1226-1232. doi: 10.1016/j. jpeds.2015.08.035

Gottlieb, G. y Lickliter, R. (2007). Probabilistic epigenesis. Developmental Science, 10(1),
1-11. doi: 10.1111/j.1467-7687.2007.00556.x Griffiths, R. (1970). The abilities of young children: a comprehensive system of mental measurement for the first eight years of life. London: Child Development Research Centre.

Gunnarsson, B., Thorsdottir, I., Palsson, G. y Gretarsson, S. (2007). Iron status at 1 and 6 years versus developmental scores at 6 years in a well-nourished affluent population. Acta Paediatrica, 96(3), 391-395.doi: 10.1111/j.1651-2227.2007.00086.x

Haas, J. y Brownlie, T. (2001). Iron deficiency and reduced work capacity: a critical review of the research to determine a causal relationship. The Journal of Nutrition, 131, 676-688. doi: 10.1093/jn/131.2.676S

Hernández-Martínez, C., Canals, J., Aranda, N., Ribot, B., Escribano, J. y Arija, V. (2011). Effects of iron deficiency on neonatal behavior at different stages of pregnancy. Early Human Development, 87(3), 165-169. doi: 10.1016/j. earlhumdev.2010.12.006

Idjradinata, P. y Pollitt, E. (1993). Reversal of developmental delays in iron-deficient anemic infants treated with iron. The Lancet, 341(8836), 1-4. doi: 10.1016/0140-6736(93)92477-B

Jorgenson, L., Wobken, J. y Georgieff, M. (2003). Perinatal iron deficiency alters apical dendritic growth in hippocampal ca1 pyramidal neurons. Developmental Neuroscience, 25, 412-420. doi: $10.1159 / 000075667$

Kariger, P., Stoltzfus, R., Olney, D., Sazawal, S., Black, R., Tielsch, J., ... Pollitt, E. (2005). Iron deficiency and physical growth predict attainment of walking but not crawling in poorly nourished Zanzibari infants. The Journal of Nutrition, 135, 814-819. doi: 10.1093/ $\mathrm{jn} / 135.4 .814$

Knickmeyer, R., Gouttard, S., Kang, C., Evans, D., Wilber, K., Smith, J., ... Gilmore, J. (2008). A structural MRI study of human brain development from birth to 2 years. The Journal of Neuroscience, 28(47), 12176-12182. doi: 10.1523/JNEUROSCI.3479-08.2008.A

Kwik-Uribe, C., Gietzen, D., German, J., Golub, M. y Keen, C. (2000). Chronic marginal iron intakes during early development in mice 
result in persistent changes in dopamine metabolism and myelin composition. The Journal of Nutrition, 130, 2821-2830. doi: 10.1093/ $\mathrm{jn} / 130.11 .2821$

Lee, D., Strathmann, F., Gelein, R., Walton, J. y Mayer-Proschel, M. (2012). Iron deficiency disrupts axon maturation of the developing auditory nerve. The Journal of Neuroscience, $32(14)$, 5010-5015. doi: 10.1523/JNEUROSCI.0526-12.2012

Li, Y., Kim, J., Buckett, P., Bo, M., Maher, T. y Wessling-Resnick, M. (2011). Severe postnatal iron deficiency alters emotional behavior and dopamine levels in the prefrontal cortex of young male rats. The Journal of Nutrition, (25), 2133-2138. doi: 10.3945/jn.111.145946

Lou, J., Mai, X., Lozoff, B., Felt, B., Kileny, P., Zhao, Z. y Shao, J. (2016). Prenatal iron deficiency and auditory brainstem responses at 3 and 10 months: a pilot study. Hong Kong Journal of Paediatrics, 20(2), 71-79.

Lozoff, B., Brittenham, G.M., Viteri, F.E., Wolf, A.W. y Urrutia, J.J. (1982). Developmental deficits in iron-deficient infants: effects of age and severity of iron lack. The Journal of Pediatrics, 101(6), 948-952. doi: 10.1016/S00223476(82)80016-4

Lozoff, B., Klein, N. y Prabucki, K. (1986). Iron-deficient anemic infants at play. The Journal of Pediatrics, 7(3), 152-158.

Lozoff, B., Brittenham, G., Wolf, A., McClish, D., Kuhnert, P., Jimenez, E., ... Krauskoph, D. (1987). Iron deficiency anemia and iron therapy effects on infant developmental test performance. Pediatrics, 79(6), 981-995.

Lozoff, B., Jimenez, E. y Wolf, A. (1991). Longterm developmental outcome of infants with iron deficiency. New England Journal of Medicine, 325, 687-694. doi: 10.1056/ NEJM199109053251004

Lozoff, B., Wolf, A. y Jimenez, E. (1996). Iron-deficiency anemia and infant development: effects of extended oral iron therapy. The Journal of Pediatrics, 129(3), 382-389. doi: 10.1016/ S0022-3476(96)70070-7

Lozoff, B., Klein, N., Nelson, E., McClish, D., Manuel, M. y Chacon, M. (1998). Behavior of infants with iron deficiency anemia. Child Development, 69(1), 24-36. doi: 10.1111/ j.1467-8624.1998.tb06130.x

Lozoff, B., Jimenez, E., Hagen, J., Mollen, E. y Wolf, A. (2000). Poorer behavioral and developmental outcome more than 10 years after treatment for iron deficiency in infancy. Pediatrics, 105(4), 1-11. doi: 10.1542/peds.105.4.e51

Lozoff, B., Jimenez, E. y Smith, J. (2006). Double burden of iron deficiency in infancy and low socioeconomic status: a longitudinal analysis of cognitive test scores to age 19 years. Archives of Pediatrics and Adolescent Medicine, 160(11), 1108-1113. doi: 10.1001/ archpedi.160.11.1108

Lozoff, B., Clark, K., Jing, Y., Armony-Sivan, R., Angelilli, M. y Jacobson, S. (2008). Dose-response relationships between iron deficiency with or without anemia and infant social-emotional behavior. The Journal of Pediatrics, 152(5), 696-702. doi: 10.1016/j. jpeds.2007.09.048

Lozoff, B., Armony-Sivan, R., Kaciroti, N., Jing, Y., Golub, M. y Jacobson, S. (2010). Eye-blinking rates are slower in infants with iron-deficiency anemia than in nonanemic iron-deficient or iron-sufficient infants. The Journal of Nutrition, 140(5), 1057-10561. doi: 10.3945/ jn.110.120964

Lozoff, B., Smith, J., Clark, K., Perales, G., Rivera, F. y Castillo, M. (2010). Home intervention improves cognitive and social-emotional scores in iron-deficient anemic infants. Pediatrics, 126(4), 884-894. doi: 10.1542/ peds.2009-3535

Lozoff, B., Smith, J., Kaciroti, N., Clark, K., Guevara, S. y Jimenez, E. (2013). Functional significance of early-life iron deficiency: Outcomes at 25 years. The Journal of Pediatrics, 163(5), 1260-1266. doi: 10.1016/j. jpeds.2013.05.015

Lozoff, B., Jiang, Y., Li, X., Zhou, M., Richards, B., Xu, G., ... Li, M. (2016). Low-dose iron supplementation in infancy modestly increases infant iron status at 9 mo without decreasing growth or increasing illness in a randomized clinical trial in rural china. The Journal of 
Nutrition, 146(3), 612-621. doi: 10.3945/ jn.115.223917

Lukowski, A., Koss, M., Burden, M., Jonides, J., Nelson, C., Kaciroti, N., ... Lozoff, B. (2010). Iron deficiency in infancy and neurocognitive functioning at 19 years: evidence of long-term deficits in executive function and recognition memory. Nutritional Neuroscience, 13(2), 54-70. doi: 10.1038/jid.2014.371

McCarthy, D. (1972). Manual for the McCarthy scales of children's abilities. New York: Psychological Corporation.

Mittal, R., Pandey, A., Mittal, B. y Agarwal, K. (2002).Effect of latent iron deficiency on GABA and glutamate neuroreceptors in rat brain.Indian Journal of Clinical Biochemistry, 17(2), 1-6. doi: 10.1007/BF02867966

Monga, M., Walia, V., Gandhi, A., Chandra, J. y Sharma, S. (2010). Effect of iron deficiency anemia on visual evoked potential of growing children. Brain \& Development, 32(3), 213-216. doi: 10.1016/j.braindev.2009.02.009

Moorthi, P., Premkumar, P., Priyanka, R., Jayachandran, K. y Anusuyadevi, M. (2015). Pathological changes in hippocampal neuronal circuits underlie age-associated neurodegeneration and memory loss: Positive clue toward SAD. Neuroscience, 301, 90-105. doi: 10.1016/j.neuroscience.2015.05.062

Moos, T. y Rosengren Nielsen, T. (2006). Ferroportin in the postnatal rat brain: implications for axonal transport and neuronal export of iron. Seminars in Pediatric Neurology, 13(3), 149-157. doi: 10.1016/j.spen.2006.08.003

Morath, D. y Mayer-Pröschel, M. (2002). Iron deficiency during embryogenesis and consequences for oligodendrocyte generation in vivo. Developmental Neuroscience, 24(2-3), 197-207. doi: 10.1159/000065688

Muñoz, P., Humeres, A., Elgueta, C., Kirkwood, A., Hidalgo, C. y Núñez, M. (2011). Iron mediates N-Methyl-D-aspartate receptor-dependent stimulation of calcium-induced pathways and hippocampal synaptic plasticity. The Journal of Biological Chemistry, 286(15), 13382-13392. doi: 10.1074/jbc.M110.213785

Nelissen, E., De Vry, J., Antonides, A., Paes, D.,
Schepers, M., van der Staay, F., ... Vanmierlo, T. (2017). Early-postnatal iron deficiency impacts plasticity in the dorsal and ventral hippocampus in piglets. International Journal of Developmental Neuroscience, 59, 47-51. doi: 10.1016/j.ijdevneu.2017.03.006

Olney, D., Pollitt, E., Kariger, P., Khalfan, S., Ali, N., Tielsch, J., ... Stoltzfus, R. (2007). Young Zanzibari children with iron deficiency, iron deficiency anemia, stunting, or malaria have lower motor activity scores and spend less time in locomotion. The Journal of Nutrition, 137(12), 2756-2762. doi: 137/12/2756

Ortiz, E., Pasquini, J., Thompson, K., Felt, B., Butkus, G., Beard, J. y Connor, J. (2004). Effect of manipulation of iron storage, transport, or availability on myelin composition and brain iron content in three different animal models. Journal of Neuroscience Research, 77(5), 681-689. doi: 10.1002/jnr.20207

Peirano, P., Algarín, C., Garrido, M., Algarín, D. y Lozoff, B. (2007). Iron-deficiency anemia is associated with altered characteristics of sleep spindles in NRem sleep in infancy. Neurochemical Research, 32(10), 16665-16672. doi: 10.1007/s11064-007-9396-8

Peirano, P., Algarín, C., Garrido, M y Lozoff, B. (2007). Iron deficiency anemia in infancy is associated with altered temporal organization of sleep states in childhood. Pediatric Research, 62(6), 715-719. doi: 10.1203/PDR. 0b013e3181586aef

Pollitt, E., Golub, M., Gorman, K., Grantham-Mcgregor, S., Levitsky, D., Schürch, B., ... Bundy, D. (1996). A reconceptualization of the effects of under nutrition on children's biological, psychosocial and behavioural development. Social Policy Report, 10(5), 1-22.

Postle, B.y D'Esposito, M. (1999). Dissociation of human caudate nucleus activity in spatial and non spatial working memory: An event-related fMRI study. Cognitive Brain Research, 8(2), 107-115.doi: 10.1016/S0926-6410(99)00010-5

Rao, R. y Georgieff, M. (2001). Neonatal iron nutrition. Seminars in Neonatology, 6(5), 425-435.doi: 10.1053/siny.2001.0063

Rao, R., Tkac, I., Townsend, E., Gruetter, R. 
y Georgieff, M. (2003). Perinatal iron deficiency alters the neurochemical profile of the developing rat hippocampus. The Journal of Nutrition, 133(10), 3215-3221. doi: 10.1093/ $\mathrm{jn} / 133.10 .3215$

Rao, R. y Georgieff, M. (2007). Iron in fetal and neonatal nutrition. Seminarsin Fetal Neonatal Medicine, 12(1), 54-63. doi: 10.1016/j. siny.2006.10.007

Reyes, H., Guiscafré, H., Muñoz, O., PérezCuevas, R., Santoyo, R. y Gutiérrez, G. (1998). Factores asociados a incumplimiento terapéutico y costo del desperdicio de antimicrobianos en infección respiratoria alta y diarrea aguda Fármacos, 1, 10-13.

Rivera, F. y Walter, T. (1996). Efecto de la anemia ferropriva en el lactante sobre el desarrollo psicológico del escolar. Revista Chilena de Pediatría, 67(4), 141-147.

Roncagliolo, M., Garrido, M., Walter, T., Peirano, P. y Lozoff, B. (1998). Evidence of altered central nervous system development in infants with iron deficiency anemia at 6 mo: delayed maturation of auditory brainstem responses. The American Journal of Clinical Nutrition, 68(3), 683-690. doi: 10.1093/ajcn/68.3.683

Rosato-Siri, M., Marziali, L., Guitart, M., Badaracco, M., Puntel, M., Pitossi, F., ... Pasquini, J. (2017). Iron availability compromises not only oligodendrocytes but also astrocytes and microglial cells. Molecular Neurobiology, 55(2), 1068-1081. doi: 10.1007/s12035-0160369-2

Santos, D., Angulo-Barroso, R., Li, M., Bian, Y., Sturza, J., Richards, B. y Lozoff, B. (2018). Timing, duration, and severity of iron deficiency in early development and motor outcomes at 9 months. European Journalof Clinical Nutrition, 72(3), 332-341. doi: 10.1038/s41430017-0015-8

Shafir, T., Angulo-Barroso, R., Calatroni, A., Jimenez, E. y Lozoff, B. (2006). Effects of iron deficiency in infancy on patterns of motor development over time. Human Movement Science, 25(6), 821-838. doi: 10.1016/j. humov.2006.06.006

Shafir, T., Angulo-Barroso, R., Jing, Y., Angelilli,
M., Jacobson, S. y Lozoff, B. (2008). Iron deficiency and infant motor development. Early Human Development, 84(7), 479-485.doi: 10.1016/j.earlhumdev.2007.12.009

Shafir, T., Angulo-Barroso, R., Su, J., Jacobson, S. y Lozoff, B. (2009). Iron deficiency anemia in infancy and reach and grasp development. Infant Behaviorand Development, 32(4), 366-375. doi: 10.1016/j.infbeh.2009.06.002

Stoltzfus, R., Kvalsvig, J., Chwaya, H., Montresor, A., Albonico, M., Tielsch, J., ... Pollitt, E. (2001). Effects of iron supplementation and anthelmintic treatment on motor and language development of preschool children in Zanzibar: double blind, placebo controlled study. The BMJ, 323, 1-8. doi: 10.1136/ bmj.323.7326.1389

Tamura, T., Goldenberg, R., Hou, J., Johnston, K., Cliver, S., Ramey, S. y Nelson, K. (2002). Cord serum ferritin concentrations and mental and psychomotor development of children at five years of age. The Journal of Pediatrics, 140(2), 165-170. doi: 10.1067/mpd.2002.120688

Thompson, D., Wood, S., Doyle, L., Warfield, S., Lodygensky, G., Anderson, P., ... Inder, T. (2008). Neonate hippocampal volumes: prematurity, perinatal predictors, and 2-year outcome. Annalsof Neurology, 63(5), 642-651. doi: 10.1002/ana.21367

Thompson, D., Adamson, C., Roberts, G., Faggian, N., Wood, S., Warfield, S., ... Inder, T. (2013). Hippocampal shape variations at term equivalent age in very preterm infants compared with term controls: perinatal predictors and functional significance at age 7. Neuroimage, 70, 278-287.doi: 10.1016/j.humov.2008.02.015. Changes

Walker, S., Wachs, T., Meeks, J., Lozoff, B., Wasserman, G., Pollitt, E. y Carter, J. (2007). Child development: risk factors for adverse outcomes in developing countries. The Lancet, 369, 145-157.doi: 10.1016/S01406736(07)60076-2

Walter, T., De Andraca, I., Chadud, P. y Perales, C. (1989). Iron deficiency anemia: adverse effects on infant psychomotor development. Pediatrics, 84(1), 7-17. 
WHO. (2001). Iron deficiency anaemia: assessment, prevention and control, a guide for program managers. Geneva: WHO.

WHO.(2011). Haemoglobin concentrations for the diagnosis of anaemia and assessment of severity. Geneva: WHO.
WHO. (2015). The global prevalence of anaemia in 2011. Geneva: WHO.

WHO.(2016). WHO recommendation on antenatal care for positive pregnancy experience. Geneva: WHO.

Recibido: 23 de noviembre de 2017 Aceptado: 21 de septiembre de 2019 